\title{
Policy and Economic
} Frameworks to Deepen Sino-Saudi Cooperation 


\section{About KAPSARC}

The King Abdullah Petroleum Studies and Research Center (KAPSARC) is a non-profit global institution dedicated to independent research into energy economics, policy, technology and the environment across all types of energy. KAPSARC's mandate is to advance the understanding of energy challenges and opportunities facing the world today and tomorrow, through unbiased, independent, and high-caliber research for the benefit of society. KAPSARC is located in Riyadh, Saudi Arabia.

This publication is also available in Arabic.

\section{Legal Notice}

(C) Copyright 2020 King Abdullah Petroleum Studies and Research Center ("KAPSARC"). This Document (and any information, data or materials contained therein) (the "Document") shall not be used without the proper attribution to KAPSARC. The Document shall not be reproduced, in whole or in part, without the written permission of KAPSARC. KAPSARC makes no warranty, representation or undertaking whether expressed or implied, nor does it assume any legal liability, whether direct or indirect, or responsibility for the accuracy, completeness, or usefulness of any information that is contained in the Document. Nothing in the Document constitutes or shall be implied to constitute advice, recommendation or option. The views and opinions expressed in this publication are those of the authors and do not necessarily reflect the official views or position of KAPSARC. 


\section{Key Points}

he workshop, "Policy and Economic Frameworks to Deepen Sino-Saudi Cooperation," held on July 2, 2019, reviewed the evolution of China's Belt and Road Initiative (BRI) and its impact on Saudi Arabia, with the goal of improving bilateral policy frameworks and economic integration under BRI and Saudi Vision 2030. It was the third in a series that seeks to increase understanding around industrial development and energy transition in the two countries.

The workshop focused on three themes:

Investing in future energy systems: Under the BRI, China's outward direct investment (ODI) in energy has evolved beyond the need to secure resources to a broader set of strategic ambitions. Manufacturing and infrastructure projects have gradually overshadowed the once-dominant role of energy ODI in the initiative, while green power collaboration among BRI economies is also growing in importance and exhibiting significant potential for carbon emissions reduction. This includes the efforts of building an 'investor-centric' ecosystem in Saudi Arabia to encourage foreign investment in renewable energy parks and related local manufacturing capacity.

Opportunities in energy efficiency improvement: Policies to cut domestic oil consumption offer huge potential for Saudi Arabia to improve its fiscal sustainability and control its domestic carbon dioxide $\left(\mathrm{CO}_{2}\right)$ emissions. The Kingdom has the opportunity to set high-profile national targets for reduced oil usage to drive wider change in the energy sector. Energy price reforms introduced since 2016 have proven effective, initiating shifts in investment and consumer behavior that have helped reduce energy use. Deeper structural changes would benefit from the support of a public funding transfer scheme for industries and will require the government to reshape its role in creating and improving the energy efficiency market.

Integrating the petrochemical supply chain: The petrochemical industry is facing a range of challenges, from oil price volatility and tighter environmental regulations to international trade conflicts and increasing geopolitical uncertainty. Given complementary competitive advantages and mutual interests, Saudi Arabia and China could drive the joint development of their petrochemical sectors, and in turn their wider economic growth, in three ways: (1) encouraging bilateral investment in chemical production, (2) increasing collaboration in research and innovation to maintain their industrial competitiveness and address their sustainability challenges, and (3) removing trade barriers - in particular through finalizing a China-Gulf Cooperation Council free trade agreement. 


\section{Summary}

he Belt and Road Initiative (BRI) has expanded from 65 original member states during its official launch in 2015 to 131 as of April 2019. The countries of the Middle East and North Africa have generally welcomed the initiative and its goal of improving regional connectivity. However, each economy has a different capacity to benefit from the BRI, depending on its size, structure, level of development, and various idiosyncratic features. These characteristics, in turn, shape BRI investments and programs for each host country and their related bilateral (and multilateral) engagement with China, such as the creation of joint action plans, the adjustment of governance structures, and the development of institutional capacity and policy frameworks.

The integration of the BRI and Saudi Vision 2030 (SV2030), the Kingdom's strategic roadmap for economic diversification, represents a key avenue for bilateral cooperation. To enhance the nonoil industrial sector and boost bilateral trade and investment, the Saudi government could reduce the costs related to compliance with local content initiatives and Saudization policies, while the Chinese government could ease restrictions on outward direct investment (ODI) to BRI economies.

'Green' power projects, a growing focus for Chinese ODI, stand out as another high potential area for bilateral cooperation under the BRI and SV2030. Renewable energy investment is accelerating in most $\mathrm{BRI}$ economies, but significant obstacles remain, including a lack of available financing and a limited local manufacturing base for supplying the necessary technology; these constraints are particularly acute for small-scale projects. To mitigate these challenges, the BRI could facilitate the integration of energy sectors and energy resource planning among the Middle East and North Africa (MENA) economies and BRI countries more broadly. Specifically, the Kingdom's roadmap for renewable energy development and its newly established 'investorcentric' ecosystem offer promising areas for BRI investments, including into 35 planned renewable energy parks and local manufacturing capacity.

Saudi Arabia has recognized the necessity of strengthening its competitiveness while simultaneously reducing wasted energy and improving energy efficiency in the industrial sector. This opens an opportunity for the government to set a system of high-profile national targets, supported by the enforcement of energy efficiency standards and financial incentives for the development of energy efficient and green technologies. However, after incubating the energy efficiency market through energy price reforms, and improving supervisory and certification systems, the authorities are expected to gradually liberalize the market as it matures.

The petrochemical sectors of both countries will benefit from increasing bilateral investment and research partnerships. This will help to boost their trade in chemicals, raise industry competitiveness, and address sustainability challenges. Greater cooperation can also lead to innovations in areas such as the efficiency and yield of chemicals, plastic packaging, and recovering and re-purposing plastic waste. Finalizing a free trade agreement (FTA) between the Gulf Cooperation Council (GCC) and China would have a significant impact on the petrochemical trade between China and Saudi Arabia as the reduction (or elimination) of tariff and non-tariff barriers would greatly expand the access of Saudi chemical producers to the Chinese market. However, negotiations have dragged on for years and may not be easy to conclude. Business collaboration offers a more attainable way to develop closer ties, which could help close the gap in the FTA negotiations. For example, China and Saudi Arabia could invest in joint ventures in the petrochemical sectors of both countries, as well as in other BRI economies. 


\section{Background to the Workshop}

his is the third in a series of workshops conducted by KAPSARC that examine

China's Belt and Road Initiative (BRI) from the perspective of Saudi Arabia and Saudi Vision 2030's strategic roadmap. The events aim to increase the understanding of key policies and driving forces around industrial development and energy transition in Saudi Arabia and China.

This workshop built on two previous ones: "Fostering Joint Leadership on Energy Productivity Transitions in Saudi Arabia and China," which took place in December 2017, and "China's Policy Drivers of Future Energy Demand," held in July 2018.
The one-day forum in Riyadh on July 2, 2019, brought together over 30 experts from government agencies, research institutes and industrial groups. Participants reviewed the progress of bilateral collaboration in renewable energy and energy efficiency and analyzed investment opportunities related to the evolving petrochemical sector. The interactive roundtable discussion further examined the value of integrating BRI with SV2030 and how this can be achieved. 


\section{Evolution of the BRI and its Impact on Saudi Arabia}

Che membership of the BRI has expanded from 65 countries during its official launch in 2015, to 131 as of April 2019. At its inception, the initiative focused on two major economic corridors: a 'Silk Road Economic Belt' across Eurasia and a '21st-Century Maritime Silk Road' linking China with South and Southeast Asia, and the MENA region. The subsequent inclusion of countries from greater Africa, the Caribbean basin, the South Pacific, and Central and South America reflects the BRI's open-ended design and its ambitions. In addition, more than 30 international organizations have signed cooperation agreements with China under the BRI.

For many governments, the BRI has catalyzed greater policy focus and investment into regional connectivity. Numerous MENA countries have connected their economic growth strategies with the BRI through physical, institutional, or people-topeople linkages (Figure 1). However, policymakers can accelerate and deepen economic integration through longer-term and more systematic planning. This will require intense efforts - bilaterally and in some cases multilaterally - to develop joint action plans, adjust existing governance structures, and build new institutional and policy frameworks.

Trade facilitation agreements have a significant impact on the economics of the BRI. Among the regional groupings of the original $65 \mathrm{BRI}$ economies, the Association of Southeast Asian Nations (ASEAN) and western Asia achieved the fastest growth in trade and the largest mergers and acquisitions flow between 2014 and 2018. Efficient trade facilitation between this bloc and China has played an important part in the growth of the ASEAN economies. Globally, outdated and overly

Figure 1. Bridging the BRI with national development strategies in MENA countries.

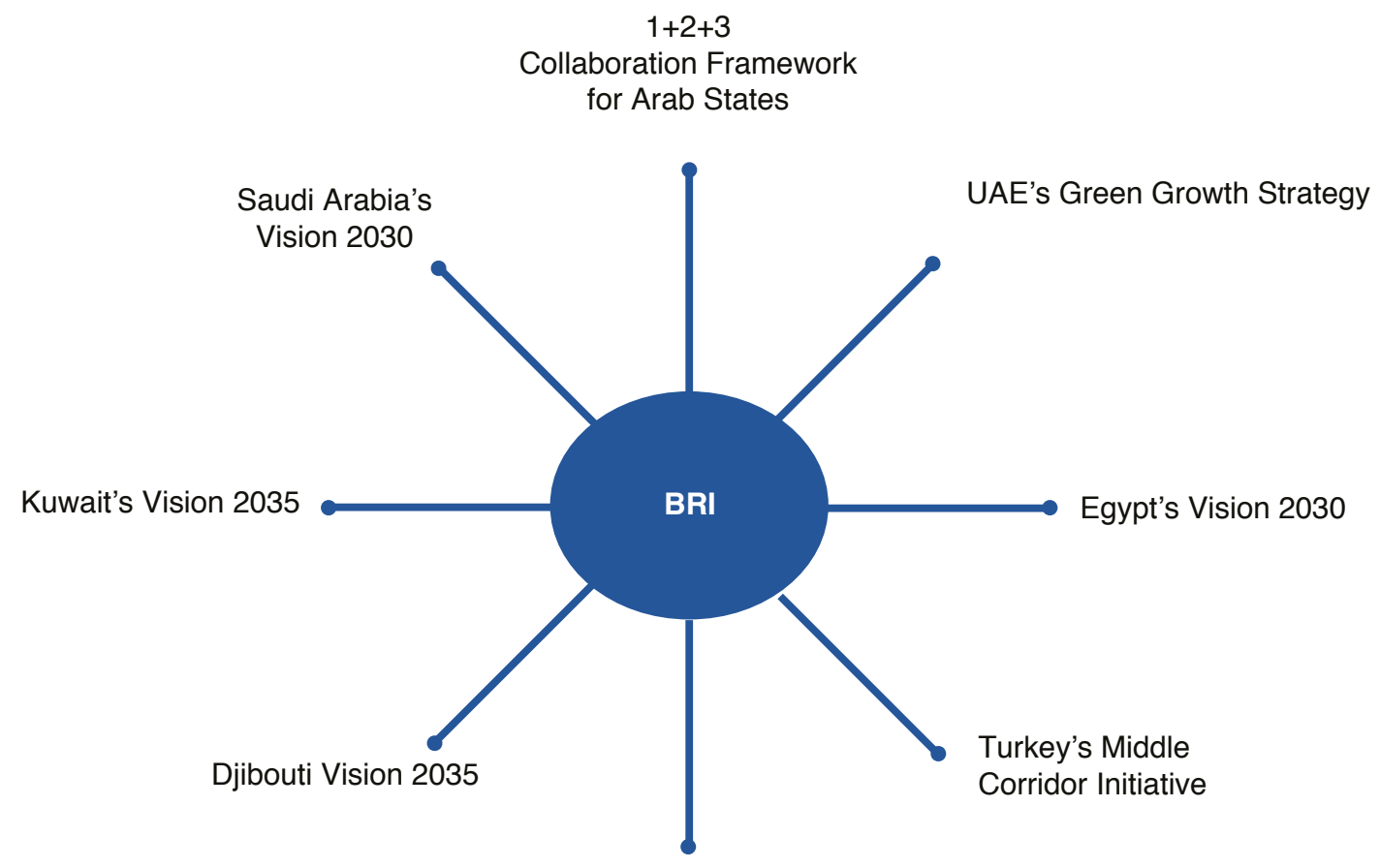

Source: KAPSARC.

Qatar's National Vision 2030 
bureaucratic procedures imposed by customs and other border management agencies are now seen as posing a greater barrier to trade than increased trade tariffs. This demonstrates the importance of improving trade facilitation in parallel with investing in physical infrastructure to maximize the economic benefits of the BRI.

The basic characteristics of BRI investment and engagement tend to be similar across member countries. However, differences in the sizes and structures of their economies, their levels of development, and the nature and organization of their governments and institutions, among other features, shape how and the extents to which each can benefit from the BRI. To assess the level of integration between Saudi Arabia and China, the KAPSARC study presented in the workshop applied five key metrics, namely: policy cooperation, trade integration, foreign direct investment integration, financial integration and people-to-people exchange. The analysis shows that the two countries have substantially strengthened bilateral ties over the past decade. It also identifies three key areas in which deeper cooperation would bring significant economic benefits: transitioning from traditional oil and gas to new low carbon technologies, advancing the petrochemical industry and value chain, and expanding the capacities of the local construction and industrial sectors.

The integration of the BRI and SV2030, Saudi Arabia's strategic roadmap for economic development, could strengthen the Kingdom's domestic supply chain, shifting more of the industrial sector's 'value-added' production within its borders.

Figure 2. FDI flows between China and Saudi Arabia.

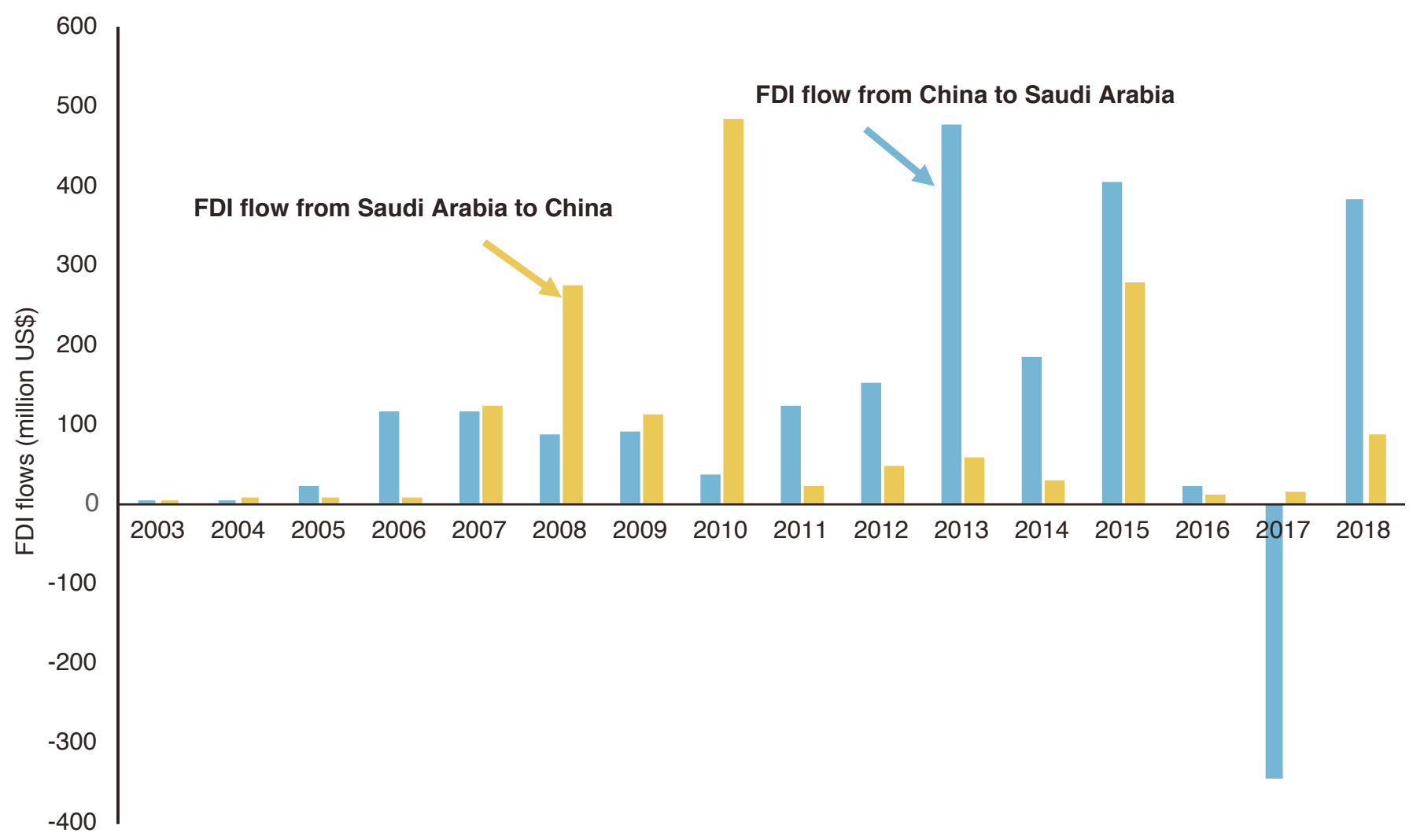

Source: KAPSARC, based on CEIC data. 
At the governmental and strategic partnership level, a growing number of collaborative projects between the two countries are either under discussion or at the planning stage. These projects could create jobs for Saudi nationals and bring other important benefits, such as insulating Saudi Arabia from any shocks to the oil market.

However, the concern of foreign investors about increased costs arising from local content initiatives and Saudization policies may impede the growth of foreign direct investment (FDI) in the Kingdom. The significant decline of FDI from China to Saudi Arabia in 2016 and a US\$345 million negative flow of FDI in 2017 (Figure 2) partly reflected the initial response of foreign investors to policy changes in Saudi Arabia. This situation was improved in 2018 when the government endeavored to establish an investorcentric ecosystem in the Kingdom. Continued efforts will be needed from the Saudi government to balance and coordinate the objective of increasing job opportunities for Saudi nationals with expanding non-oil sectors. Relaxing and streamlining the regulations on ODI for $\mathrm{BRI}$ economies is an important issue for the Chinese government, as its long-term plan to liberalize China's domestic economy and financial markets promises to foster stronger economic links with BRI economies by reducing regulatory hurdles. 


\section{Investing in Future Energy Systems}

$\mathrm{U}$ nder the BRI, China's energy investment is geographically diversified and exhibits a similar risk profile to the country's energy ODI into non-BRI economies. ASEAN economies are the recipients of more than $50 \%$ of China's total green-field energy investment under BRI, with Indonesia as the largest recipient. The Commonwealth of Independent States and ASEAN account for around $30 \%$ of China's cross-border mergers and acquisitions in the energy sector, led by Kazakhstan. Chinese SOEs dominate the country's large-scale overseas energy investments, likely due in large part to competitive advantages in capital-intensive infrastructure projects and their high risk tolerance for operating in politically and/or economically unstable environments in some BRI economies. State-owned firms also benefit from their links to the Chinese government in a variety of ways, including securing contracts and access to financing.

China's energy ODI is no longer driven primarily by the need to secure resources. Under the BRI, energy investments play a central role in China's broader economic development goals. These include increasing regional infrastructure and trade connectivity, internationalizing the renminbi (RMB) and strengthening the global roles of China-led financial institutions. The BRI's growing emphasis on manufacturing and infrastructure projects has gradually eroded the once-dominant role of energy, which accounts for below $40 \%$ of annual ODI to 65 BRI economies as of 2018 , from a peak of $70 \%$ in 2009.

The BRI has been criticized for its heavy investment in coal power projects, contravening the traditional notion of Chinese energy ODI as a tool for enhancing energy security through acquiring foreign energy resources. China has been trying to mitigate overcapacity in its domestic coal production and reduce the share of coal in its energy mix. For countries with abundant coal resources along the Belt and Road, such as Indonesia and Kazakhstan, coal remains one of the most affordable options to meet their growing energy demand. In these countries, China has invested in projects that use advanced coal-power generation technologies.

Green energy projects and initiatives show high potential for China-Saudi Arabia cooperation. Renewable energy accounts for a growing share of overall BRI energy investment, and it is estimated that 1.94 terawatts (TW) of renewable capacity could be installed in BRI economies by 2030 , with the potential to reduce annual carbon dioxide $\left(\mathrm{CO}_{2}\right)$ emissions by 780 million tonnes. Integrated energy resources planning and demand-side management could reduce $\mathrm{CO}_{2}$ emissions by a further 1 billion tonnes. However, to achieve such targets, several challenges must be addressed. These include the dearth of available financing options, the limited capacity for local manufacturing and services support, and the poor economic performance of small-scaled projects.

For Saudi Arabia, renewable energy is integral to the long-term economic goals under SV2030. The government has an ambitious plan to increase the share of renewables in its energy mix. To accomplish this, it will develop more than 35 industrial parks for renewable energy generation (e.g., wind and solar power farms) and the production of supporting equipment and technology (Figure 3). This will not only diversify the Kingdom's energy mix but also localize the manufacturing of some renewable energy capital goods that would otherwise be imported from outside of the Kingdom. The plans include eight production facilities for renewable energy equipment (five wind and three solar) that could potentially export to the wider MENA market. 
Figure 3. Development plans for 35+ parks in Saudi Arabia by 2030.

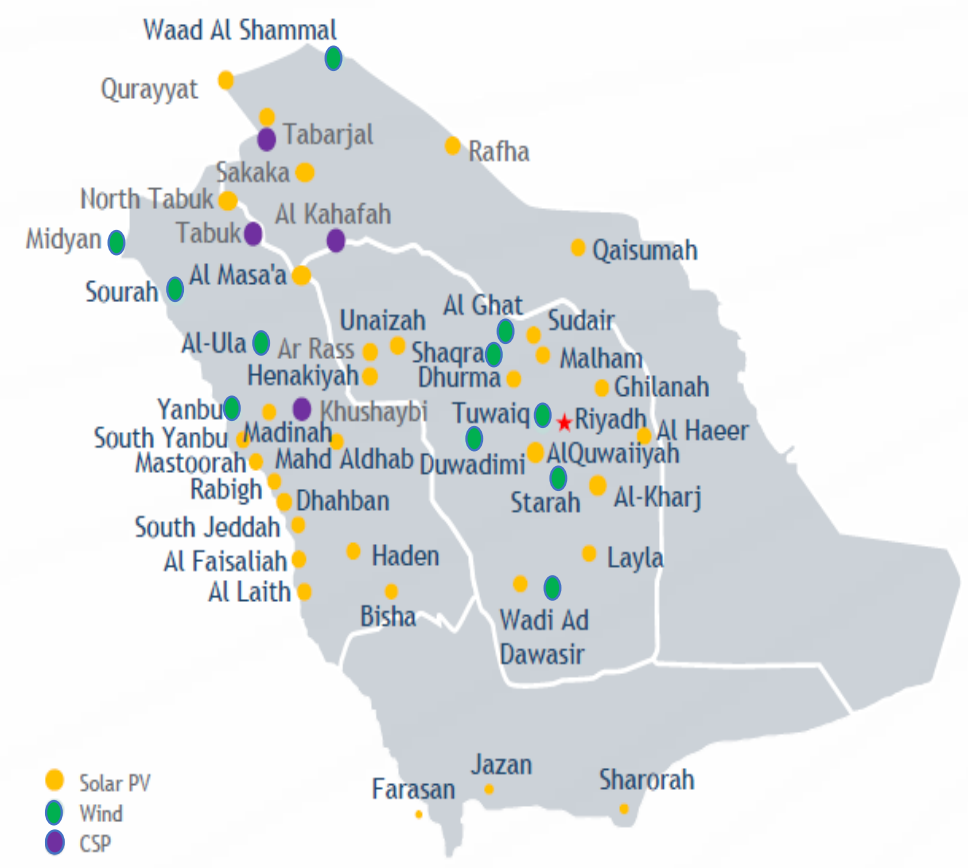

Source: National Renewable Energy Program, Saudi Arabia.

The Kingdom aims to create an investor-centric ecosystem and has already taken steps to boost investor confidence and attract more FDI, which is especially important for renewable energy. Among key factors affecting the deployment of new energy technology in the country, the government has made its most significant progress on the institutional and regulatory framework, clearly defining the roles of the authorities and offering a wide range of incentives for private investors. The government has also launched a variety of other initiatives to support green energy investment. An online data portal now covers key segments of renewable energy development, increasing transparency and efficiency in the investment process. The Renewable Energy Resources Atlas supports project siting, design and research related to green energy. The online database of local suppliers for products and services offers international developers direct access to on-theground expertise and guidance, making it easier to comply with local content requirements. The Etimad platform consolidates all government tenders and procurement, and simplifies procedures for suppliers.

Looking to the future, the government's infrastructure and industrial development plans will combine to improve power grid connection in the Kingdom and drive innovation in the areas of microgrids, energy storage, carbon capture and storage, and hydrogen development. The active involvement of Chinese institutes and investors in this process, including researching the plan, designing the pilot, building local technical capacity, and expanding the market with $\mathrm{BRI}$ economies, would be helpful for the transition toward green energy systems in both China and Saudi Arabia. 


\section{Opportunities in Energy Efficiency Improvement}

$\mathbf{F}$ rom 1990 to 2016, energy consumption and $\mathrm{CO} 2$ emissions in Saudi Arabia nearly quadrupled, while gross domestic product (GDP) rose only 2.5 times and the population size doubled. The joint study by KAPSARC and the Energy Research Institute (ERI) of China's National Development and Reform Commission estimated the Kingdom could double its GDP by 2030 and quadruple it by 2050 compared to the level of 2015 . Under the baseline scenario, the energy demand in Saudi Arabia would climb by the same two-times and four-times factors, respectively. As of 2018, average daily oil production in the Kingdom stands at 9.6 million barrels per day (Mb/d), and daily consumption reaches up to $2.6 \mathrm{Mb} / \mathrm{d}$ at its summer peak.

The baseline scenario raises a worrying question: If domestic energy demand were to quadruple by 2050, what would happen to the capacity for oil exports?

Reducing domestic oil consumption could be the most critical policy area for achieving fiscal sustainability and controlling domestic $\mathrm{CO} 2$ emissions in Saudi Arabia. Under the 'enhanced' energy conservation scenario, in which energy efficiency measures are applied across all sectors, the Kingdom could reduce its energy intensity by $25 \%$ by 2030 and $45 \%$ by 2050 , from 3.9 tonnes of oil equivalent per dollar at 2010 prices currently.

However, energy efficiency policy can be a doubleedged sword for energy-intensive industries if it is not carefully designed and implemented. Historically, low-cost energy and feedstocks have established competitive advantages for the Kingdom's energyintensive industries, namely petrochemicals, steel and cement, which will remain critical sources of growth as the country transitions away from its overreliance on oil exports.
Establishing national energy efficiency targets is the most important policy to consider when structuring energy efficiency policy frameworks. Had China maintained the same level of energy intensity growth since 1980, the country's energy consumption as of 2018 would have been more than four times as high. The government's administrative system in China has played a major role in setting national energy efficiency targets and assessing their progress at different levels. They have been supported by the legislative system and financial incentives, formulating and enforcing energy efficiency standards, and providing fiscal subsidies, tax reductions and special awards for energy efficiency projects and technology development. As a result of this energy policy framework, energy consumption per unit of major industrial products fell significantly from 1980 to 2016 : $46 \%$ for steel products, $45 \%$ for cement, and $60 \%$ for ethylene. However, it is important to note that the role of government will change significantly over the lifespan of the policies discussed above, as initial restructuring efforts eventually give way to a liberalized energy market, allowing the authorities to cease disruptive regulatory interventions.

Energy price reform has proven to be a critical step toward sustainable energy consumption. A two-phase rise in energy prices in Saudi Arabia has led to a $13 \%$ reduction in domestic oil usage from around $3 \mathrm{Mb} / \mathrm{d}$ in 2015 to around $2.6 \mathrm{Mb} / \mathrm{d}$ in 2018 (Figure 4). During this period, electricity prices for residential consumption levels below 6,000 kilowatthours ( $\mathrm{kWh}$ ) per month have risen sharply from Saudi riyals (SAR) 0.05/kWh to SAR 0.18/kWh; the cost of transport fuels, meanwhile, tripled. To offset the adverse impacts on low-income groups - both directly from more expensive fuel and electricity and indirectly from the resulting increase 
in the costs of goods and services - the government has implemented cash transfer programs and already paid more than SAR 40 billion to 3.76 million accounts since January 2018. Of this total, 50\% compensate citizens for the increase in fuel and electricity costs.

Future price reforms may become more challenging as the government seeks to bring the prices of industrial fuels toward international benchmarks. As industrial firms gradually lose their access to below-market price energy and feedstocks, they will be forced to innovate, take greater advantage of economies of scale, and optimize their supply chains. Rising energy prices will also encourage investments in higher efficiency equipment and processes. To minimize the adverse impacts of higher energy and feedstock prices on industry, the government could develop a public funding transfer scheme that supports businesses in a similar way to the Citizen's Account Program, which provides cash transfers to households, in part as a replacement for low energy prices.

\section{Energy efficiency financing can accelerate the} reform process. Globally, only one third of energy efficiency projects are on the balance sheet through self-finance, lease finance or debt finance. The other two-thirds would be off the balance sheet, creating opportunities for external investment, for example through energy performance contracts and largescale government programs. A so-called 'SuperESCO' is already established for the building sector in Saudi Arabia. This could be used to build equity financing structures for industrial energy efficiency projects.

Figure 4. Impacts of energy price reform on domestic energy consumption.

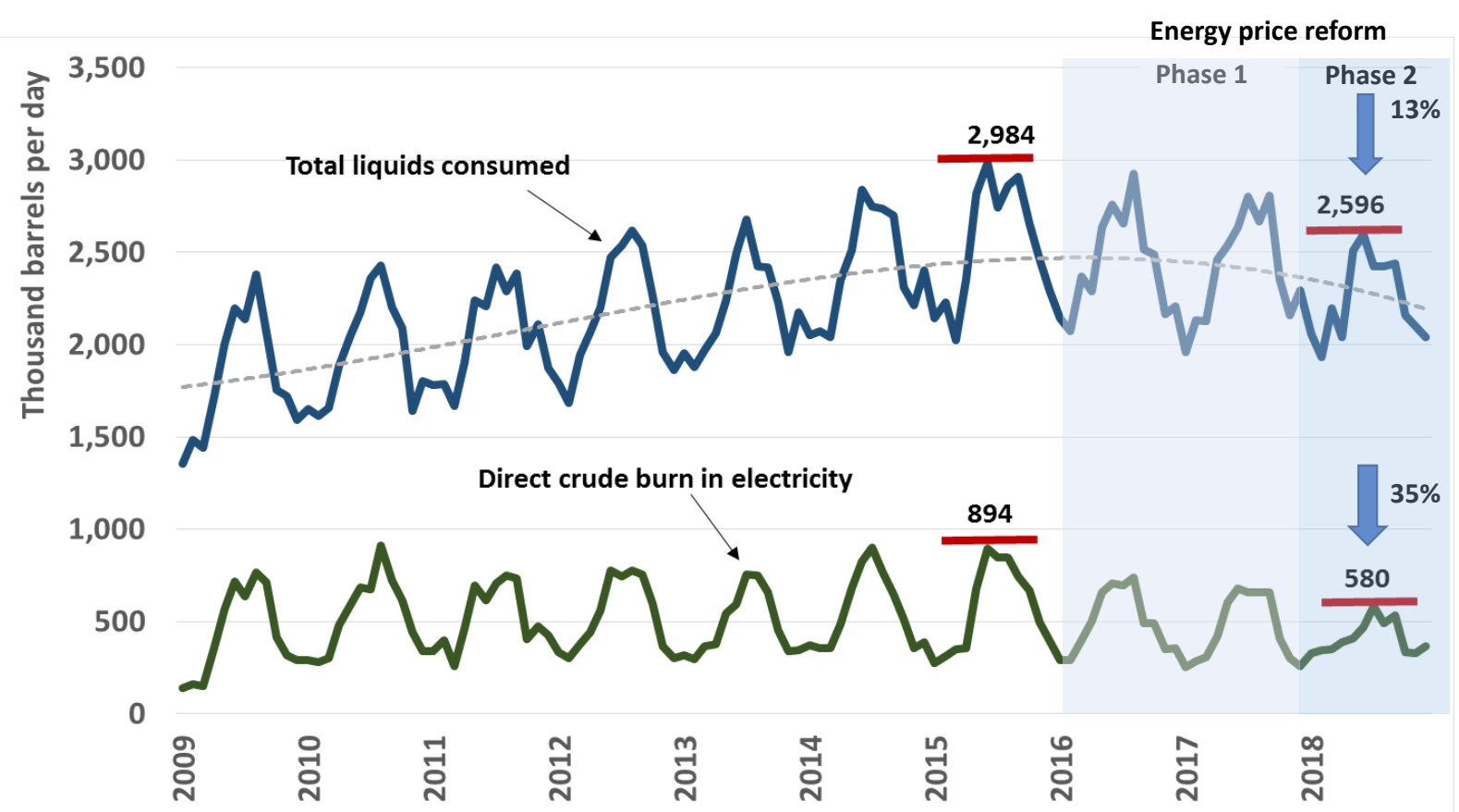

Source: KAPSARC based on Joint Organisations Data Initiative (JODI) data. 


\section{Integrating the Petrochemical Supply Chain}

O ver the last two decades, China and Saudi Arabia have led the world in petrochemical production growth, with China's global share of production tripling and Saudi Arabia's doubling from 2000 to 2018. The coming decades will see output continue to rise in both countries, driven by economic growth. However, the petrochemical industry faces myriad challenges arising from oil price volatility, stricter environmental regulations, international trade conflicts, and increasing geoeconomic and geopolitical uncertainty. These issues have strategic implications for deepening collaboration between the petrochemical sectors of China and Saudi Arabia.

\section{Increasing bilateral investment to drive future economic growth}

Saudi chemical producers have invested in China since 1994. The biggest growth in investment has come in the last decade in the form of large-scale joint ventures with Chinese partners in Fujian, Tianjin, Liaoning and Ningxia. The total value of Saudi FDI into China's petrochemical sector is reaching US\$ 35 billion, which could generate 21.7 million tonnes of chemicals per year by 2025 . It is forecast that Chinese market demand for ethylene and paraxylene (PX), the two main petrochemical intermediates, will peak at 72 million tonnes per year and 41 million tonnes per year, respectively, around 2040, while demand for crude oil and refined products start to decline around 2030 (Figure 5).

Meanwhile, Chinese producers are expanding their investments in Saudi Arabia's petrochemical sector with projects such as the Jazan industrial city joint venture. The total value of Chinese FDI into the Kingdom's petrochemical industry is approaching US $\$ 12.5$ billion, which would add 5 million tonnes of chemical production in the Kingdom by 2025.

Figure 5. Petroleum and petrochemical demand in China.

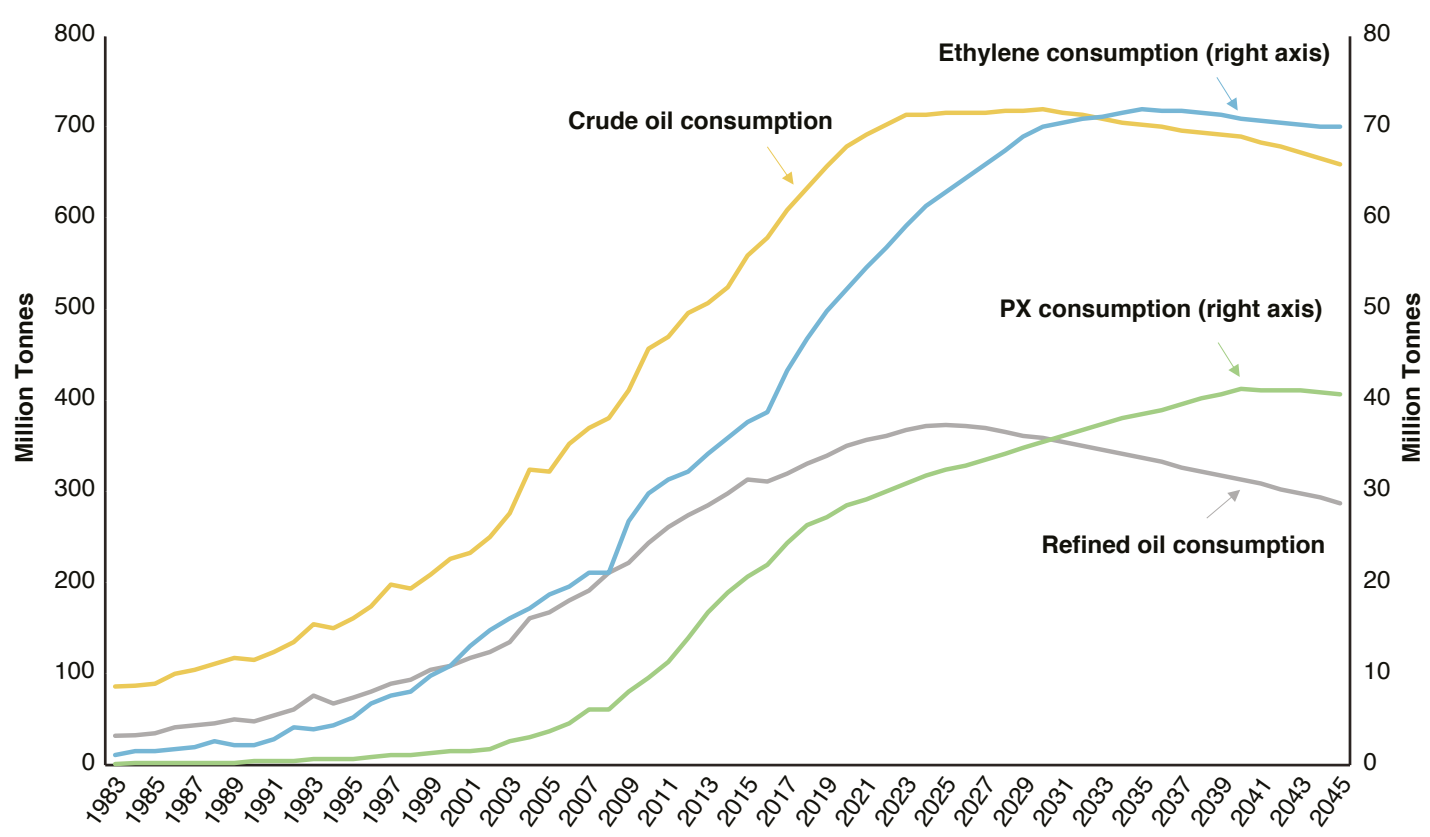

Source: KAPSARC workshop presentation. 
As Saudi Arabia diversifies its economy beyond oil and gas exports, the petrochemicals sector will become even more critical. Under SV2030, the National Industrial Development and Logistics Vision Realization Program set targets in early 2019 to increase the localization of the basic and intermediate chemical supply chain to $70 \%$, develop specialized chemical manufacturing clusters, and double the domestic production capacity of plastic and packaging products.

As petrochemical markets continue to grow in China and Saudi Arabia, investment in local production facilities will become an increasingly effective pathway to leverage the two countries' advantages in access to resources and technology, and to improve the talent and expertise of their labor pools.

\section{Innovation needed for competitiveness and sustainability}

Innovation is a strategic imperative for the petrochemical industries of China and Saudi Arabia. Research and development (R\&D) ventures present opportunities for bilateral investment in pursuit of more advanced capabilities, technical know-how, and technology to achieve economic, environmental and social benefits. High potential areas for collaboration could include efforts to increase the efficiency and yield of chemicals and the development of advanced process technologies such as crude oil-to-chemicals techniques. As environmental regulations tighten, it will become increasingly necessary for chemical producers to develop new application grades for 'greener' plastic packaging and design innovative ways to recover and re-purpose plastic waste.

Joint research centers established over the last decade reflect a new era of China-Saudi Arabia cooperation and provide a successful model for bilateral cooperation on innovation. Saudi Basic Industries Corporation (SABIC) built its R\&D center in Shanghai in 2013, Saudi Aramco established its Beijing Research Center in 2015, and SINOPEC set up its R\&D center in Dhahran Techno Valley in Saudi Arabia in 2016. Moreover, joint research and talent exchange programs initiated by leading petrochemical producers are helping to seed future innovation in both countries. These include SABIC's collaborations with the Dalian Institute of Chemical Physics and Chinese Academy of Sciences, and Saudi Aramco's strategic partnerships with Tsinghua University and China University of Petroleum in Beijing.

\section{Lower trade barriers and greater business collaboration offer mutual benefits}

China is the largest trading partner for Saudi Arabia's chemical industry, accounting for $25 \%$ of the Kingdom's exports from this sector as of 2017. Saudi Arabia, in turn, is the third-largest trading partner for China, accounting for $8.3 \%$ of the latter's chemical imports. China's chemical imports from Saudi Arabia have risen steadily over the last quarter century, from 0.3 million tonnes in 1992 to 10 million tonnes in 2017. These chemical shipments exhibit significant structural change over this period, shifting from $75 \%$ concentration in fertilizers to consisting almost entirely (98\%) of polymers and petrochemical intermediates. Looking to the future, the chemicals trade between Saudi Arabia and China is expected to evolve as the industry responds to the change of global market and domestic development strategy. Furthermore, if the trade war between China and the United 
States (U.S.) remains unresolved, Saudi producers will have the opportunity to provide substitutes for key petrochemical intermediates and polymers that China currently imports from the U.S.

In contrast with the rapid rise in China-Saudi Arabia trade and investment, the negotiation of the FTA between the Gulf Cooperation Council (GCC) and China has progressed slowly since talks began 15 years ago. One of the major obstacles has been China's opposition to the liberalization of the petrochemicals trade, largely due to the input cost advantages enjoyed by petrochemical producers in Saudi Arabia and other GCC countries. For example, the cost of producing ethylene, polyethylene and glycol in Saudi Arabia is only about a third of the cost in China, and it costs about 25\% less for Saudi Arabia to produce polypropylene. Therefore, unrestricted trade in petrochemicals would have an enormous negative impact on the sector in China, including the potential loss of large numbers of jobs. However, petrochemical joint ventures and research collaborations, as described above, offer less controversial steps toward establishing a common ground that could serve as a foundation for the FTA. 


\section{About the Workshop}

APSARC convened the workshop, "Policy and Economic Frameworks to Deepen Sino-Saudi Cooperation," in Riyadh on July 2, 2019. It was attended by more than 30 experts from government, industry and academia, and held under a modified version of the Chatham House Rules. Participants consented to be listed below. However, none of the content in this briefing can be attributed to any individual attendee.

\section{List of participants}

Alexander Ablaza - Co-chair, Asia-Pacific ESCO Industry Alliance

Moodi Alotaibi - Economics Lecturer, Princess Nourah bint Abdulrahman University, KSA

Amar Amarnath - Director for Energy Information Management Program, KAPSARC

Hatem Al Atawi - Intern, KAPSARC

Elizabeth Carey - Senior Research Associate, KAPSARC

Dongmei Chen - Research Fellow, KAPSARC

Xuang Cheng - General Manager, Industrial and Commercial Bank of China (ICBC), Riyadh Branch

Yande Dai - Former Director General, Energy Research Institute, National Development \& Reform Commission (NDRC), China

Xiaochang Feng - Research Analyst, Natural Resources Defense Council, Beijing Office, China

Philipp Galkin - Visiting Researcher, KAPSARC

Bandar Al-Ghamdi - Research Associate, King Faisal Center for Research and Islamic Studies

Nicholas Howarth - Research Fellow, KAPSARC

Kutani Ichiro - Senior Researcher, Institute of Energy Economics, Japan

Dong Jiang - Head of Corporate Banking Department, ICBC, Riyadh Branch
Xiaoming Ke - Deputy Chief Engineer, Sinopec Economics \& Development Research Institute, China

Tao Ma - Deputy Director of International Political Economy, Institute of World Economics and Politics, Chinese Academy of Social Sciences (CASS)

Fuad Mosa - Vice President, Local Content \& Business Development, SABIC, KSA

Jawaher Al-Moummer - Saudi Center for International Strategic Partnership

Abdulrahman Al-Mugairin - Saudi Center for International Strategic Partnership

Abdulwahab Al Saadoun - Secretary General, Gulf Petrochemicals and Chemicals Association

Khalid Al Saleh, Consultant - King Abdullah City for Atomic and Renewable Energy, KSA

Adam Sieminski - President, KAPSARC

Pieter Smeets - Senior Manager, Industrial Sustainability, Corporate Sustainability Department, SABIC, KSA

Fahad Al-Sulaiman - Director, Center of Research Excellence in Renewable Energy and Energy Efficiency, King Fahd University of Petroleum \& Minerals, KSA

Guodong Sun - Research Fellow, KAPSARC

Li Sun - Research Fellow, CNPC Economics \& Technology Research Institute, China

Lei Tian - Associate Professor, Energy Research Institute, NDRC, China

Fahad M. Al Turki - Vice President for Research, KAPSARC

Yongzhong Wang - Director, Division of World Energy, Institute of World Economics and Politics, CASS

Colin Ward - Interim Director for Markets \& Industrial Development Program, KAPSARC

Jiao Yu - Vice President, Sinopec Economics \& Development Research Institute, China

Lin Zhang - Researcher, Institute of World Economics and Politics, CASS 
Notes

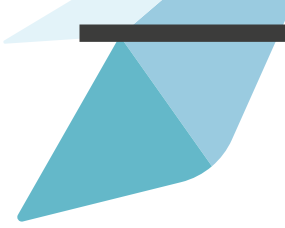




\section{Notes}

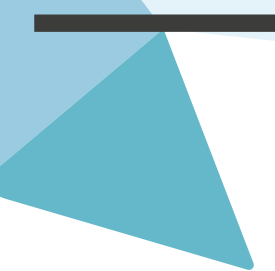




\section{About the Team}

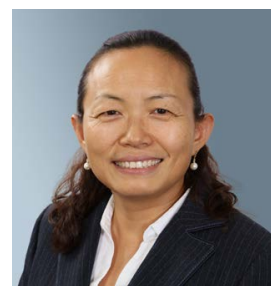

\section{Dongmei Chen}

Dongmei is a research fellow at KAPSARC, focusing on China-related policy studies and partnership coordination. She has more than 20 years of experience in the energy and climate fields, acting as Head of the Institute of Industrial Productivity China Office and Director of Climate Change \& Energy Program for WWF China before joining KAPSARC.

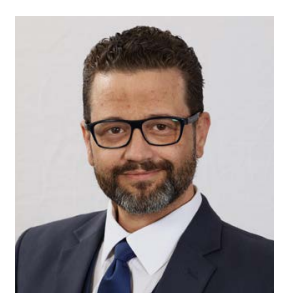

\section{Colin Ward}

Colin is the Interim Director of the Markets and Industrial Development Program at KAPSARC. He has worked in the energy industry for 10 years in various capacities, including seismic field work, refinery design and consulting for major international and national oil companies. Colin plays a major role in several KAPSARC projects, primarily focusing on cost estimation for energy projects and environmental impacts of the global energy industry. He holds an MBA (University of Texas), a B.S. in Electrical Engineering (University of Houston), and a B.A. in Philosophy (Tulane University).

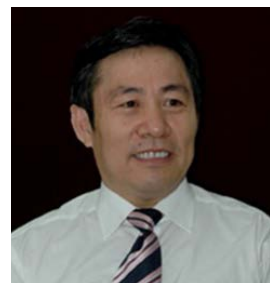

\section{Yande Dai}

Professor Dai is a senior research fellow at the Energy Research Institute (ERI), National Development and Reform Commission, China. He joined the ERI in 1982 and acted as Deputy Director General from 2003 to 2016 and Director General in 2016-2017. His research focuses on energy economics, energy development strategy, energy conservation planning and climate change policies. He holds a B.S. in Basic Organic Chemical Industry from China Petroleum University (Huadong).

\section{About the Project}

Announced by Chinese President Xi Jinping in 2013 and officially launched by the Chinese government in March 2015 as the Vision and Actions on Jointly Building Silk Road Economic Belt and 21st Century Maritime Silk Road, China's evolving Belt and Road Initiative (BRI) has become a subject of interest across the spheres of business, academia and government. This project assesses the overall progress of bilateral collaboration between China and Saudi Arabia, with a special focus on energy-sector outward direct investment, the energy transition, and opportunities beyond fossil fuels. It aims to improve policy frameworks for economic integration between China's BRI and Saudi Vision 2030. 
INAPSARC

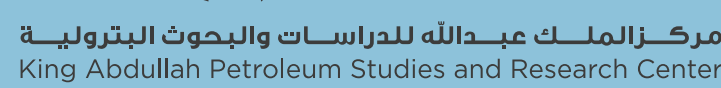

www.kapsarc.org 